\title{
Adolescentes com dificuldades relacionadas à saúde mental, moradores de áreas rurais: percepçóes sobre família, escola e contexto de moradia
}

\author{
Maria Fernanda Barboza Cid, Letícia Maria Pereira
}

Departamento de Terapia Ocupacional, Universidade Federal de São Carlos - UFSCar, São Carlos, SP, Brasil.

\begin{abstract}
Resumo: Objetivo: O estudo objetivou identificar as percepções de adolescentes moradores de uma área rural, vinculados a uma Unidade de Saúde da Família, com dificuldades relacionadas à saúde mental, sobre suas relações com familiares e amigos, escola, situações de estresse e apoio que vivenciam, bem como em relação à região onde residem, e compará-las com as percepções de adolescentes, também moradores de áreas rurais, que não apresentam dificuldades relacionadas à saúde mental. Método: Foram participantes dez adolescentes moradores de uma área rural de uma cidade do interior do Estado de São Paulo, divididos em dois grupos, A e B, respectivamente, com e sem dificuldades relacionadas à saúde mental. Os dados foram coletados a partir de um questionário de identificação e de um roteiro de entrevista semiestruturado, e analisados pela técnica de análise de conteúdo. Resultados: Os resultados indicaram que, na visão dos participantes, a família é apontada como a principal fonte de apoio, sendo que, no grupo de adolescentes com dificuldades relacionadas à saúde mental, ela é indicada também como importante fonte de estresse. A escola é vista como um espaço de socialização para os adolescentes. Sobre o contexto de moradia, as percepções são predominantemente positivas, sendo que um dos aspectos negativos se refere à falta de opções de lazer. Conclusão: Foi possível observar poucas diferenças na percepção dos dois grupos a respeito das questões abordadas. O contexto de moradia, embora seja apontado como restrito, parece garantir o pertencimento a grupos e ambientes, o que pode ter um papel protetivo no enfrentamento do sofrimento psíquico.
\end{abstract}

Palavras-chave: Adolescente, Saúde Mental, População Rural.

\section{Adolescents with mental health challenges residents of rural areas: perceptions about family, school and neighborhood context}

\begin{abstract}
Objective: This study aimed to identify the perceptions of adolescents residents in a rural area, linked to a Family Health Unit due mental health challenges, about their relationships with family and friends, school, situations of stress and support experience, as well about the region where they live, and compare them with the perceptions of adolescents also residents in a rural area who don't have mental health challenges. Method: The study included 10 adolescents residents in a rural area of a city in São Paulo state, divided in two groups, A e B (with and without mental health challenges). Data were collected from questionnaire identification and a semi-structured interview and analyzed using analysis of contents. Results: The results indicated that, in view of the participants, the family is considered the main source of support, and in the group of adolescents with mental health challenges it is indicated also as an important source of stress. The school is seen, generally, as a socialization space for teens. About neighborhood context, perceptions are predominantly positive, and one of the reported negative aspects refers to the lack of leisure facilities. Conclusion: We observed few differences in the perception of both groups on the issues addressed. The neighborhood context, although it is appointed as restricted in terms of activities possibilities, seems to guarantee membership in groups and environments, which may have a protective role in coping with psychological suffering.
\end{abstract}

Keywords: Adolescent, Mental Health, Rural Population.

\footnotetext{
Autor para correspondência: Maria Fernanda Barboza Cid, Departamento de Terapia Ocupacional, Universidade Federal de São Carlos, Rodovia Washington Luís, Km 235, SP-310, CEP 13565-905, São Carlos, SP, Brasil, e-mail: mariafernandacid@gmail.com

Recebido em Ago. 12, 2015; 1ª Revisão em Jan. 12, 2016; Aceito em Maio 9, 2016.
} 


\section{Introdução}

A saúde mental pode ser considerada um estado de bem-estar, no qual o indivíduo percebe as suas capacidades, consegue lidar com o estresse normal do cotidiano, pode trabalhar de uma forma produtiva e é capaz de contribuir positivamente para sua comunidade, ou seja, é uma condição que abrange aspectos, como o bem-estar subjetivo, a autoeficácia percebida, a autonomia e a competência (WORLD..., 2001; CID, 2011).

Prejuízos na esfera da saúde mental, de acordo com Sá et al. (2013), podem gerar um mal-estar inespecífico, com repercussões fisiológicas e psicológicas que aparecem, muitas vezes, de forma sutil, mas que têm o poder de atingir o cotidiano do indivíduo, em suas relaçóes, comportamentos e emoçôes, prejudicando assim sua qualidade de vida e favorecendo o surgimento de outros transtornos e manifestaçôes psicopatológicas.

Estudos de caráter longitudinal têm apontado uma continuidade das dificuldades socioemocionais ao longo da vida, de forma que grande parte dos adultos que vivenciam problemas de saúde mental apresentam os primeiros sinais na infância ou adolescência (CID; MATSUKURA, 2014; AMSTALDEN et al., 2010), apontando e reforçando que estes períodos correspondem a uma fase da vida em que intensas e rápidas transformaçóes ocorrem no indivíduo (LEONE; GALLO, 2010). Apesar disto, a atenção à saúde mental de crianças e adolescentes, e seu reconhecimento como uma questão de saúde pública ainda é recente, assim como também são recentes e escassos os estudos na área da saúde mental infantojuvenil (MATSUKURA et al., 2014; DELFINI; REIS, 2012).

A respeito do que está envolvido na condição da saúde mental de crianças e adolescentes, estudos têm apontado, como fatores de risco para a saúde mental na população infantojuvenil, as condições socioeconômicas desfavoráveis, como pobreza, desemprego e baixa escolaridade; características do ambiente familiar, como violência intrafamiliar, estilos parentais negativos e vivência de problemas de saúde mental pelos cuidadores, especialmente nas mães (AVANCI et al., 2007; CID; MATSUKURA, 2014; MATSUKURA et al., 2014; FLEITLICH; GOODMAN, 2000, 2001; PAULA et al., 2010; SÁ et al., 2010; VITOLO et al., 2005).

De acordo com a Organização Mundial da Saúde, viver em áreas rurais ${ }^{1}$ também pode estar relacionado a prejuízos na saúde mental, devido às características deste contexto, como o isolamento, a falta de transporte e comunicaçóes, e as oportunidades educacionais e econômicas limitadas, bem como - e especialmente - a dificuldade de acesso a serviços de saúde mental; essas condiçóes são apontadas como dificuldades comuns neste contexto (WORLD..., 2001, p. 13).

Poucos estudos realizados em países em desenvolvimento, como o Brasil, têm examinado e comparado a situação da saúde em geral e da saúde mental de pessoas que residem e/ou trabalham em áreas rurais (FARIA et al., 2000; PAFFER et al., 2012), especialmente da população infantojuvenil.

Em consultas às bases de dados Scielo e Biblioteca Virtual da Saúde, realizadas entre os meses de maio e junho de 2014, com as palavras-chave "saúde mental" e "rural", e "sofrimento psíquico" e "rural", foram encontrados nove artigos nacionais (COSTA; LUDERMIR, 2005; FARIA et al., 1999; GOMES; ROZEMBERG, 2000; GOODMAN et al., 2005; PAFFER et al., 2012; ROZEMBERG, 1994; SÁ et al., 2013; SCHMIDT; GODINHO, 2006; SEIXAS et al., 2010), que focalizavam a temática da saúde mental de populaçóes rurais, sendo que, destes, dois tratavam da população infantojuvenil e são apresentados a seguir (GOODMAN et al., 2005; SÁ et al., 2013).

Goodman et al. (2005) desenvolveram um estudo que teve como objetivos principais avaliar a utilização de instrumentos diagnósticos em saúde mental em uma área rural e comparar os resultados obtidos com os resultados de uma pesquisa anterior (FLEITLICH; GOODMAN, 2004) realizada em Taubaté, interior de São Paulo, com crianças e adolescentes de áreas urbanas e rurais. Como resultado, o estudo indicou que as crianças e os adolescentes da área rural investigada (Ilha da Maré-BA) apresentavam mais dificuldades relacionadas à saúde mental quando comparadas às crianças e aos adolescentes participantes do estudo realizado em Taubaté, porém tais dificuldades apresentaram um menor impacto negativo sobre suas vidas; contudo, o estudo náo encontrou uma explicação para tal fato, indicando a necessidade de estudos posteriores (GOODMAN et al., 2005).

Sá et al. (2013) realizaram uma pesquisa de caráter qualitativo, que focalizou adolescentes moradores de uma regiáo rural no Estado do Rio de Janeiro e teve como objetivo identificar alguns aspectos individuais, sociais e familiares vinculados à saúde mental nos 22 adolescentes participantes. Os-adolescentes apontam como principal problema em suas vidas os danos causados pelas enchentes, que são comuns à região onde vivem. Outro resultado relevante é a percepção da família, pelos adolescentes, como principal rede de apoio e auxílio. 
No âmbito internacional, Gamm, Stone e Pittman (2003) apontam que a taxa de prevalência de sofrimento psíquico na população infantojuvenil dos Estados Unidos é estimada em 20\%; contudo, crianças e adolescentes de áreas rurais tendem a estar em desvantagem quanto à oferta de serviços de atenção à saúde mental, especialmente para transtornos emocionais graves, o que ocorre principalmente por causa da relativa falta de psiquiatras, especialmente de psiquiatras infantis, em áreas rurais.

Um relatório conjunto de órgãos públicos relacionados à juventude em Victória, na Austrália, realizado em 2002, com o objetivo de reunir o conhecimento existente acerca das questóes enfrentadas pelos jovens que vivem em áreas rurais, apontou que alguns dos aspectos comuns das áreas rurais que podem contribuir para o agravamento de situaçôes de sofrimento psíquico dos jovens incluem a desaceleraçáo da economia rural, o aumento do desemprego, os níveis mais baixos de escolaridade, os desastres naturais, menos diversidade e oportunidades de contato social, a dificuldade de acesso aos serviços de saúde e menos opçóes e oportunidades de transportes e locomoção. Já os aspectos das áreas rurais que podem promover a saúde mental destes jovens são a sensação de conexão e pertencimento com a comunidade, e a percepção de redes de apoio social (DAVIES et al., 2002).

De forma geral, a partir da análise da literatura apresentada, observa-se um caráter epidemiológico da maioria dos estudos e o fato de os mesmos náo focalizarem a realidade da população infantojuvenil residente em áreas rurais. Identifica-se, portanto, a necessidade de investigaçóes que explorem a saúde mental dos moradores da área rural, no sentido de conhecer e compreender melhor seu contexto e suas peculiaridades, visando a contribuir com reflexões e discussóes que subsidiem políticas e serviços de saúde destinados a tal população.

O presente estudo, de caráter exploratório, vai nessa direção, na medida em que busca compreender, a partir da voz dos adolescentes com e sem dificuldades relacionadas à saúde mental, moradores de uma área rural, suas percepçóes sobre a realidade familiar, escolar e de moradia, que vivenciam no cotidiano.

\section{Objetivos}

O presente estudo teve por objetivo identificar as percepções de adolescentes moradores de uma área rural, vinculados a uma Unidade de Saúde da Família por conta de dificuldades relacionadas à saúde mental, a respeito de suas relações com familiares e amigos, escola, situaçôes de estresse e apoio que vivenciam, bem como a respeito da região onde residem, e compará-las com as percepçóes de adolescentes também moradores de áreas rurais que náo apresentam dificuldades relacionadas à saúde mental.

\section{Método}

\subsection{Participantes}

Participaram do estudo dez adolescentes, com idade variando entre 12 e 17 anos, moradores de uma área rural localizada em um município com cerca de 235 mil habitantes, do interior do Estado de Sáo Paulo. Estes adolescentes foram divididos em dois grupos, sendo um grupo constituído por adolescentes vinculados à Unidade de Saúde da Família do local por apresentarem dificuldades relacionadas à saúde mental (grupo A), e o outro grupo formado por adolescentes que não vivenciam tais dificuldades (grupo B). Ambos os grupos contaram com cinco participantes cada.

Nas tabelas 1 e 2, são descritos os dados gerais dos participantes.

Sobre os participantes com dificuldades relacionadas à saúde mental, estes foram identificados pelos profissionais da USF de referência dos participantes, por apresentarem queixas ligadas a sintomas depressivos, dificuldades comportamentais e déficits de atenção e/ou hiperatividade. Observa-se que, embora estivessem vinculados à USF por conta destas dificuldades, os jovens não apresentavam diagnósticos fechados em seus prontuários.

Tabela 1. Dados gerais dos participantes do grupo A.

\begin{tabular}{|c|c|c|c|c|c|}
\hline Participante & Idade & Gênero & Frequenta a escola & Série & Situação conjugal \\
\hline A1 & 15 anos & M & Sim & $1^{\circ}$ ano Ens. Médio & Solteiro \\
\hline A2 & 17 anos & F & Sim & $2^{\circ}$ ano Ens. Médio & Mora com o companheiro \\
\hline A3 & 17 anos & F & não & $1^{\circ}$ ano Ens. Médio & Mora com o companheiro \\
\hline A4 & 14 anos & F & Sim & $9^{\circ}$ ano & Solteira \\
\hline A5 & 14 anos & M & Sim & $9^{\circ}$ ano & Solteiro \\
\hline
\end{tabular}


Tabela 2. Dados gerais dos participantes do grupo B.

\begin{tabular}{|c|c|c|c|c|c|}
\hline Participante & Idade & Gênero & Frequenta a escola & Série & Situação conjugal \\
\hline B1 & 15 anos & F & Sim & $1^{\circ}$ ano Ens. Médio & Solteira \\
\hline B2 & 12 anos & F & Sim & $7^{\circ}$ ano & Solteira \\
\hline B3 & 16 anos & M & Sim & $1^{\circ}$ ano Ens. Médio & Solteiro \\
\hline B4 & 17 anos & M & Sim & $9^{\circ}$ ano & Solteiro \\
\hline B5 & 13 anos & M & Sim & $8^{\circ}$ ano & Solteiro \\
\hline
\end{tabular}

\subsection{Local}

O estudo foi realizado em uma Unidade de Saúde da Família de um distrito rural pertencente a um município de cerca de 235 mil habitantes do interior do Estado de São Paulo e nas residências dos participantes, que se localizavam, além do distrito em questão, também em bairros rurais da mesma região.

\subsection{Instrumentos de coleta de dados}

Para a coleta de dados, foram utilizados: i) um questionário de identificação do adolescente, contendo informaçóes gerais, tais como dados de identificação, composição familiar, escolaridade do participante e da família, e ocupação dos pais e do adolescente; ii) um roteiro de entrevista semiestruturado, contendo questôes que buscaram abordar a percepção dos adolescentes a respeito de suas relaçôes com familiares e amigos, escola, situaçóes de estresse e apoio que vivenciam, bem como a respeito da regiâo onde residem.

Ambos os instrumentos foram elaborados pelas pesquisadoras e passaram por um processo de adequação a partir da participação de juízes especialistas - pesquisadores e profissionais do campo da saúde mental infantojuvenil -, que avaliaram a pertinência das questốes colocadas ao que se pretendia verificar, conforme aponta Manzini (2002).

\subsection{Procedimentos}

O projeto foi apresentado à Secretaria Municipal de Saúde do município em questão e sua realização foi autorizada. Feito isso, o projeto foi submetido ao Comitê de Ética em Pesquisas em Seres Humanos da UFSCar, recebendo parecer favorável, pelo CAAE: 16335413.6.0000.5504.

A localizaçáo dos integrantes do grupo de adolescentes com dificuldades relacionadas à saúde mental se deu por meio do contato com os profissionais de uma Unidade de Saúde da Família (USF) localizada em um distrito rural do município, que indicaram possíveis participantes. Observa-se que o critério de participação referente a estes adolescentes e levados em consideração pelos profissionais da USF foi estarem vinculados à USF por conta de dificuldades relacionadas à saúde mental.

O grupo de adolescentes sem a vivência de dificuldades relacionadas à saúde mental foi composto através da indicação dos profissionais da USF ou dos próprios adolescentes participantes do outro grupo. Aponta-se que tais adolescentes não precisariam ter vínculo formal com a USF.

A coleta de dados ocorreu na residência dos participantes e se deu mediante assinatura do Termo de Consentimento Livre e Esclarecido tanto pelos adolescentes quanto pelos responsáveis. Nesta ocasião, foram apresentados, ao adolescente, os instrumentos de coleta de dados. Observa-se que as entrevistas foram gravadas em áudio pela pesquisadora.

As entrevistas gravadas foram transcritas na íntegra e, após leitura exaustiva do material, realizou-se um desmembramento dos relatos em unidades de registro (temas) e posterior categorização e análise do conteúdo que, segundo Bardin (2006), trata-se de uma técnica, ou conjunto de técnicas, que analisam e interpretam o conteúdo manifesto das verbalizaçóes por meio de procedimentos sistemáticos e objetivos. O interesse reside no que o conteúdo pode oferecer ao investigador após ser tratado e classificado.

Assim, as unidades de registro foram organizadas por meio de temas (previamente definidos no roteiro de entrevista semiestruturada) e, em seguida, foi feita a categorização do conteúdo (elaboração de categorias) presente nas unidades de registro, a partir da correspondência entre a significação (sentidos existentes) no conteúdo das unidades de registro e a literatura da área (BARDIN, 2006).

\section{Resultados}

Os resultados obtidos dizem respeito às percepçóes que os adolescentes dos dois grupos apresentaram a respeito das temáticas a seguir:

1. Percepções a respeito das relações familiares;

2. Percepção sobre relaçóes com os amigos; 
3. Percepção sobre a escola;

4. Aspectos que considera positivos na vida;

5. Aspectos que considera difíceis na vida;

6. Percepçôes sobre o bairro/regiáo onde vive.

A seguir, apresentam-se os resultados referentes a cada temática.

\subsection{Percepções acerca das relações familiares}

Os participantes relatam ter contato com os familiares que residem ou não na mesma casa. É importante ressaltar que, a partir dos relatos, foi possível observar que três participantes do grupo $\mathrm{A}$ qualificam a relação com seus familiares, focando em aspectos conflitantes desta relação. Já no grupo B, todos os participantes qualificam a relaçáo com os familiares a partir de aspectos positivos.

A seguir, apresenta-se a tabela 3 com as categorias obtidas e o número de participantes relacionadas a estas. Em seguida, trechos de falas ilustrativas dos participantes acerca desta temática.

\subsubsection{Categoria 1}

Me relaciono mais com os da casa mesmo. A minha relação é boa com os dois. (Participante do grupo A).

Com meu pai é muito bem, com a minha mãe também, com os meus irmãos também, e com os tios a gente tá sempre do lado aqui, meus tios são gente boa. (Participante do grupo B).

\subsubsection{Categoria 2}

Com a minha mãe. Minha mãe e a minha avó. Com a minha mãe, ah, antes a gente brigava bastante sabe, ai eu comecei a morar com a minha avó, e há pouco tempo eu voltei pra cá. (Participante do grupo A).

\subsection{Percepção sobre relações com os amigos}

Em relação aos amigos, verificou-se apenas uma única categoria de resposta, a saber:

Adolescentes relatam que possuem amigos e que mantêm contato com os mesmos no cotidiano

No que se refere às atividades realizadas junto aos amigos, observou-se que estas são realizadas em ambientes diversos (escola, casa, bairro) e que incluem atividades de lazer, como passeios, jogos, práticas de esportes e atividades no ambiente escolar.

Os seguintes trechos são utilizados para ilustrar estas relaçóes.

Meus amigos são a A. e ela mora em fazenda. Estuda aqui mesmo. E a G. também que é da escola,mora em fazenda. E todas elas estudam comigo. A M. também estuda e mora em fazenda [...] A gente adora fofocar! Falar mal dos outros então! Nos encontramos só na escola. De vez em quando, quando tem alguma coisa aqui eu chamo a $G$., só a $G$. que vem aqui. A A. nunca veio. (Participante do grupo A).

Os amigos são mais da escola. Os mais próximos é primo, colega mesmo... ah, mais próximo mesmo é o meu irmão ne, que a gente ta sempre junto, eu faço tudo com ele né... é, o I., primos, amigos lá da vila ne, o L.. Nem todos são da escola, alguns são vizinhos. É, videogame, é futebol, jogar bola. Geralmente a gente se encontra na casa deles né, vou na casa deles lá, joga bola, senão vai no campo ali. (Participante do grupo B).

\subsection{Percepção sobre a escola}

A respeito da escola, também foi observada uma única categoria nos dois grupos, a partir das falas, a saber:

Adolescentes frequentam a escola e percebem aspectos positivos e negativos sobre esse contexto

Observou-se que os adolescentes relataram percepçôes de aspectos positivos, como as festas realizadas na

Tabela 3. Relação com familiares.

\begin{tabular}{|l|c|c|}
\hline \multicolumn{1}{|c|}{ Categorias } & Participantes Grupo A & Participantes Grupo B \\
\hline $\begin{array}{l}\text { 1- Participante se relaciona com familiares que } \\
\text { moram na mesma casa ou não, e percebe aspectos } \\
\text { positivos na relação. }\end{array}$ & A1 e A5 & B1, B2, B3, B4 e B5 \\
\hline $\begin{array}{l}\text { 2- Participante se relaciona com familiares que } \\
\text { moram na mesma casa ou não, e percebe aspectos } \\
\text { conflitantes na relação. }\end{array}$ & A2, A3 e A4 & - \\
\hline
\end{tabular}


escola, alguns professores e a convivência com os colegas; também se relataram aspectos negativos, como alguns problemas de relacionamentos com colegas e certos professores. Os seguintes trechos são utilizados para ilustrar tais percepçôes:

[...] A escola, pra falar a verdade näo tem nada de divertido. Eu acho que eles deveriam fazer interclasse mais vezes. Festa junina esse ano não teve [...] Eu acho que tipo assim, como é escola, pros alunos quererem mais, participar mais na escola, eles tinham que fazer alguma coisa mais divertida [...] E reuniäo dos pais eu acho que mais pais deveriam participar. E eu acho também que eles deveriam tomar providência de, sabe, eu acho que eles tem medo de alunos que fazem coisa errada. Ah, os professores são legais, eu gosto dos professores. São ótimos professores. Já faltou, chegou a faltar professor, mas sempre tem outros que substituem. (Participante do grupo A).

Ótima. De bom é que tem várias festas, as pessoas são bem minhas amigas, e de ruim é que sempre tem algumas meninas assim sabe, que implicam, essas coisas assim. (Participante do grupo B).

Ah, dá pra ir né, você sabendo lidar com seus estudos dá pra. Eu acho que a aula que en gosto mesmo é a educação fisica, o que eu mais gosto. De ruim $e ́$, assim, eu só não gosto de alguns professores, de algumas matérias também, assim, inglês. Ah, eu acho que é mais por causa dos professores [...]. (Participante do grupo B).

\subsection{Aspectos que considera positivos na vida}

Os adolescentes foram questionados a respeito dos aspectos que consideram positivos em suas vidas e uma única categoria de resposta foi verificada em ambos os grupos, a saber:

Adolescentes consideram a família como principal aspecto positivo em suas vidas

A seguir, seguem falas dos participantes que ilustram esta categoria:
De bom, minha familia. Ah, porque minha familia éfeliz, alegre. (Participante do grupo A).

Bom, de positivo é que eu tenho a minha mäe e o meu marido né, de positivo. Porque são os únicos que conversam comigo, então éo que mais tem de positivo. (Participante do grupo A).

O mais bom é ter a familia junto, como a gente mora junto é a melhor coisa que tem na minha vida, ter a família tudo junto pra te apoiar. (Participante do grupo B).

De bom, ah, não tem o que reclamar. De bom, ah, gosto da minha família, gosto de, ah, de tudo o que eu faço, tudo que. (Participante do grupo B).

\subsection{Aspectos que considera difíceis na vida}

Quando questionados sobre aspectos que consideram difíceis em suas vidas, os participantes do grupo A apontaram, como dificuldades, as relaçóes e os conflitos familiares, e relaçôes pessoais. Já os participantes do grupo $\mathrm{B}$ apontam dificuldades mais gerais em seu cotidiano, como, por exemplo, a falta de serviços no bairro.

A seguir, é apresentada a tabela 4 com os dados obtidos, além de falas dos participantes acerca dos mesmos.

\subsubsection{Categoria 1}

Meu pai. É que, sem eu fazer nada ele me chamava de biscate, essas coisas, sem eu fazer nada, desde os 11 anos [chorando], to acostumada já. E ele falou que não gosta de mim, que não se considera como meu pai. [...] Todo dia, direto ele me batia, se eu pedisse pra sair, sabe [...] Ah, ele náo gosta de mim, sabe. (Participante do grupo A).

Na minha vida, hum, o convivio dos meus pais. Ah, eles brigam bastante, sabe. E eu me sinto mal. Acho que só. (Participante do grupo A).

Tabela 4. Aspectos que considera difíceis na vida.

\begin{tabular}{|l|c|c|}
\hline \multicolumn{1}{|c|}{ Categoria } & Participantes Grupo A & Participantes Grupo B \\
\hline $1-$ Conflitos familiares & A3 e A4 & - \\
\hline $\begin{array}{l}2-\text { Dificuldades relacionadas ao } \\
\text { local de moradia }\end{array}$ & - & B1, B2 e B3 \\
\hline $3-$ Nada/não sabe & A1 e A5 & B4 e B5 \\
\hline
\end{tabular}




\subsubsection{Categoria 2}

De dificil, é que aqui não tem nada sabe, ai de difícil é que tem que ir lá do outro lado da cidade pra comprar as coisas. (Participante do grupo B).

\subsubsection{Categoria 3}

Não sei dizer. (Participante do grupo A).

É, acho que.. agora não consigo pensar em nada. (Participante do grupo B).

\subsection{Percepções sobre o bairro/região onde vive}

Sobre as percepçóes acerca do bairro e da regiáo em que vivem, verificou-se uma única categoria nas respostas dos grupos A e B, que se refere a:

Adolescentes consideram aspectos positivos e negativos sobre o local de moradia

Observou-se que os participantes relatam tanto aspectos positivos - como a tranquilidade do local e a presença de amigos - como aspectos negativos, como a falta e a precariedade dos serviços de comércio, lazer e transporte, e a distância em relação a estes serviços, além da dificuldade de mobilidade devido às condiçôes climáticas, como chuva, e de conflitos com vizinhos (fofoca), entre outros. Ressalta-se que os relatos dos adolescentes deixam transparecer um destaque maior para os aspectos negativos da região, como pode-se observar nos trechos a seguir.

Ah, de ruim assim, nunca tem muita coisa, sabe. $E$ de bom, é um lugar quieto, isso eu acho bom. Sinto falta de festas, antes tinha bastante, agora não tem muito. (Participante do grupo A).

É bom e não é. De bom é que aqui é sossego, ninguém te incomoda. E morar na cidade tem mais pra onde sair, e aqui não, aqui é ruim. (Participante do grupo A).

De ruim é que quase não tem ninguém assim, é mais adulto. E de bom, de bom aqui, ai não sei. O que eu acho ruim, é que tem muito bicho, é que vem dos matos aí. De bom, que a minha amiga mora aqui no mesmo bairro, mas é um pouquinho longe, pra andar de a pé. (Participante do grupo B).

É o fim do mundo. De bom tem quase nada. Andar de moto aqui que pode né. Ruim nossa, tem um monte! Quando chove, fica um monte de poça de lama, cê não pode brincar pra cá, tem que ficar indo lá na vila pra jogar bola, pra encontrar com os amigos, não pode nem vir pra cá, não pode jogar bola aqui, não pode escutar som, porque os vizinhos não gostam. Lá na vila ninguém reclama de som. (Participante do grupo B).

Neste aspecto, os participantes foram questionados, ainda, sobre o que gostariam que existisse na região onde vivem e, sobre isto, todos os participantes apontam a necessidade de mais serviços, principalmente de lazer e de comércio, o que pode ser observado a seguir.

Festa. Mais festa, tipo baile, tipo alguma coisa pras crianças fazerem. Ahh, acho que tem pouca coisa, e o pouco que tem é no centro comunitário. Deveria ter mais, tipo alguma coisa pra ensinar a gente, tipo curso de artesanato, é isso. (Participante do grupo A).

Ah, queria que tivesse tudo o que tem na cidade aqui né. Ah um shopping né, loja de roupa aqui não tem, lanchonete aqui também não tem, sei lá. Sinto falta, nossa, demais né. (Participante do grupo A).

Um ginásio de esportes, um shopping, um lugar assim pra andar de bicicleta, sabe, um parque alguma coisa assim. (Participante do grupo B).

Ah, gostaria que tivesse mais internet né, porque aqui não pega, pega bem ruim. Só. Ah, colocar mais lojas assim né, porque se você precisar de alguma coisa tem que ir na cidade né, ta bom. (Participante do grupo B).

\section{Discussão}

O presente estudo teve por objetivo identificar as percepçóes de adolescentes moradores de uma área rural, vinculados a uma Unidade de Saúde da Família por conta de dificuldades relacionadas à saúde mental, a respeito de suas relações com familiares e amigos, escola, situaçóes de estresse e apoio que vivenciam, bem como a respeito da região onde residem, e compará-las com as percepções de adolescentes também moradores de áreas rurais que não apresentam dificuldades relacionadas à saúde mental.

Sobre a família, observou-se que os adolescentes - com e sem dificuldades relacionadas à saúde mental - apresentam uma percepção positiva acerca da mesma, apontando-a como o principal aspecto positivo de suas vidas e a principal fonte de apoio que possuem. 
O mais bom é ter a familia junto, como a gente mora junto é a melhor coisa que tem na minha vida, ter a família tudo junto pra te apoiar. (Participante do grupo B).

Coincidindo com os resultados aqui encontrados, está o estudo de Sá et al. (2013), que foi realizado com adolescentes também moradores de uma regiāo rural e que também encontra a família como o principal apoio para estes adolescentes. Também há o estudo de Diniz (2010), no qual os adolescentes apontam suas famílias como uma fonte de cuidado, união, com um papel importante em suas formaçôes pessoais.

A família parece exercer, assim, bastante importância na vida dos jovens que vivem em regióes rurais. Esta importância é considerada como uma das características marcantes das comunidades rurais, sendo que é, no ambiente familiar, que os jovens vão mediando e formando suas personalidades, construindo suas identidades e suas maneiras de se autoperceberem e de se autorrepresentarem (DINIZ, 2010; SILVA, 2002; VIEIRA, 2006).

Contudo, os resultados advindos das entrevistas com os adolescentes com dificuldades relacionadas à saúde mental mostram uma situação de dualidade em relação às suas famílias, pois, apesar de considerarem a família como importante em suas vidas e fonte de apoio, situaçóes de conflito familiar são apontadas como presentes, sendo percebidas como fatores negativos em suas vidas, que dificultam seu cotidiano, gerando sofrimento. Para melhor ilustrar tal fato, apresentamos aqui a fala de uma adolescente com dificuldades relacionadas à saúde mental, que, ao ser questionada sobre o que considera difícil em sua vida, aponta:

Na minha vida, hum, o convivio dos meus pais. Ah, eles brigam bastante, sabe. (Participante do grupo A).

Discorrendo brevemente sobre a família, Souza e Oliveira (2011) apontam que a mesma consiste em uma unidade de cuidado e proteçáo, limites e socialização, desempenhando papéis fundamentais para o crescimento psicológico do indivíduo. As autoras indicam que é no interior da família que os indivíduos adquirirão valores, normas, crenças, modelos e padróes de comportamento necessários para o estar na sociedade, apontando também a importância do estabelecimento de vínculos afetivos no seio familiar para o desenvolvimento saudável dos indivíduos. Neste sentido, as autoras discutem que a família, quando possuidora destas características, favorece o desenvolvimento dos adolescentes, sendo que a ausência destes aspectos e a vivência de situaçóes estressoras, associadas ao modo como a família e o adolescente lidam com isto, podem causar prejuízos ao desenvolvimento e à saúde mental destes adolescentes (SOUZA; OLIVEIRA, 2011).

A partir destes apontamentos, é possível sinalizar que, para os adolescentes com dificuldades relacionadas à saúde mental do presente estudo, as famílias são percebidas náo só como fonte de apoio, mas, também, como fonte importante de estresse, o que pode, ao longo do tempo, ter influenciado negativamente a saúde mental dos jovens aqui focalizados.

Vale a pena ressaltar que estes resultados vão ao encontro do que a literatura tem apontado a respeito da família enquanto potencial contexto de risco e/ou proteção para o desenvolvimento socioemocional das crianças (CID, 2011), bem como enquanto principal fonte de suporte social dos adolescentes (SQUASSONI, 2012).

Aponta-se, ainda, que as características familiares (sejam estas percebidas como positivas ou negativas) e as formas de interação entre os diferentes membros no contexto familiar são complexas e influenciadas por características extrafamiliares, de forma que culpabilizar a família pelo prejuízo da saúde mental de suas crianças e adolescentes é fruto de uma análise simplista e reducionista, não contribuindo para a compreensáo ampliada da realidade dos jovens em questáo.

Nessa direção, estudos têm apontado a necessidade de se avaliarem variáveis contextuais extrafamiliares que podem exercer influência na forma de os pais educarem e participarem da vida de seus filhos. Assim, pode-se considerar que as interaçóes pais/responsáveis e filhos podem sofrer influências dos aspectos sociais e históricos presentes no contexto sociocultural do indivíduo (CID, 2011; COLLINS et al., 2000).

Enfim, estes achados em relaçáo ao papel da família, como colocado para os jovens da região rural, apontam tanto para os benéficios que tais relaçóes podem trazer como também para sua relevância. Relevância que permanece, mesmo quando a família, como grupo, não é capaz de manter ou possibilitar relaçôes de apoio; neste caso, é possível que, no contexto rural, que é marcado pela menor oportunidade de alternativas de relacionamentos e espaços, implique que vivências e situaçóes familiares mais difíceis propiciem maior vulnerabilidade.

Estudos mais amplos, que considerem regióes rurais maiores e diversas, com maior número de participantes, selecionados de forma mais criteriosa, e que focalizem este aspecto, seriam relevantes para a maior compreensão do impacto do contexto familiar 
na saúde mental de crianças e adolescentes moradores de áreas rurais, na medida em que o presente estudo é exploratório e realizado em uma única região, com uma quantidade pequena de participantes, cujos resultados indicam aspectos importantes a serem mais bem investigados futuramente.

Falando agora sobre a escola, observou-se que os participantes de ambos os grupos apresentaram uma percepção predominantemente positiva acerca da escola que frequentam e que está localizada no distrito rural onde foi realizada a pesquisa. Foi possível verificar que a escola se revela nas falas, não apenas como um espaço puramente educacional, mas como um espaço relacional importante para os adolescentes, já que, muitas vezes, é apenas lá que convivem com seus amigos - que, muitas vezes, moram em regióes distantes - e com outros adolescentes.

Estes resultados condizem com o que foi encontrado em alguns estudos (DINIZ, 2010; VIEIRA, 2006), nos quais a escola também se constituiu como um dos principais contextos de interação, socialização, iniciação afetivo-sexual e diversão cotidianos, em que os jovens desenvolvem atividades de lazer e compóem sua rede de sociabilidade. Assim, podemos considerar que a escola, apesar de algumas dificuldades apontadas pelos participantes, como déficits organizacionais e um ensino que deixa a desejar, aparece como uma fonte de apoio e propicia um aumento das redes sociais dos adolescentes residentes em áreas rurais.

Este resultado permite a reflexão sobre a escola enquanto um possível contexto de proteção à saúde mental infantojuvenil. Assim, conforme apontam alguns estudos da área, a participação em atividades escolares pode ser considerada como um fator de proteção (AMPARO et al., 2008; CID, 2011; PESCE et al., 2004; SAPIENZA; PEDROMÔNICO, 2005), na medida em que é um ambiente organizador da rotina, possibilita a interação social e ajuda na criação de oportunidades de desenvolvimento pessoal e social. Além disso, de acordo com Marques e Dell'Aglio (2013), os profissionais ligados ao ambiente escolar também são considerados como fatores protetivos à saúde mental de adolescentes em sofrimento psíquico residentes em áreas rurais, exercendo o importante papel de fonte de suporte social (FRANCIS et al., 2006).

Por outro lado, em um estudo realizado com adolescentes de uma região rural do Rio de Janeiro, a escola é apontada pelos autores como um fator de risco à saúde mental dos adolescentes, já que os autores consideram que, neste ambiente, os adolescentes estão expostos a situaçóes de violência que podem prejudicá-los, destruindo a confiança na instituição, que deveria ser reconhecida naturalmente como lugar de proteção (SÁ et al., 2013).

Sobre isso, Vieira (2006) indica, ainda, um déficit da oferta de serviços educacionais no meio rural brasileiro, apontando para a necessidade da existência de uma política educacional eficaz e adequada para o campo, além da melhoria nas condiçóes de acesso e permanência na escola.

Observam-se, portanto, divergências sobre o papel do contexto escolar no desenvolvimento emocional de crianças e adolescentes, especialmente no que se refere àqueles que residem em regióes rurais. Acredita-se que o que é oferecido pela escola poderia ser potencializado, considerando a escassez de oportunidades de atividades e interaçóes sociais em outros setores (lazer, cultura, esporte), o que aproxima a expectativa em relação ao uso e às oportunidades colocadas no ambiente escolar em diversos contextos, tais como no meio rural e em regióes vulneráveis.

Nessa direção, destaca-se a necessidade de mais estudos que focalizem o papel deste contexto na vivência cotidiana de adolescentes e jovens que residem em tais regióes, considerando suas especificidades.

Sobre a região em que vivem, verificou-se que os participantes a percebem com aspectos positivos e negativos. Como aspectos positivos, são destacadas a ausência de violência, a tranquilidade do local e a presença de amigos. Wedig e Menasche (2009) também indicam esta visão positiva dos jovens acerca da região rural em que residem, destacando este ambiente como um local mais tranquilo e menos violento do que a cidade, que fornece alimentos considerados mais saborosos e saudáveis, e que possibilita cotidianamente a manutenção dos laços familiares e de amizade. Assim, esses autores nos direcionam para o que consideram uma "valorização do rural", num movimento que se intensifica no meio urbano e que também pode ser observado nos depoimentos dos jovens rurais, que identificam o rural como lugar de bem viver (WEDIG; MENASCHE, 2009). Autores internacionais também apontam que o viver em uma regiáo rural oferece aos adolescentes uma sensação de segurança e pertencimento, que é destacada como aspecto positivo (DAVIES et al., 2002; FRANCIS et al., 2006).

Os adolescentes apontam, também, aspectos negativos na região onde vivem, tais como a falta e a precariedade de serviços; a falta de diversidade nos serviços oferecidos (de lazer, comércio e transporte); a influência de condições climáticas (como a chuva) nas condiçóes de mobilidade, e os conflitos com vizinhos (como fofoca). 
As dificuldades relacionadas ao aspecto físico da região rural onde residem e a forte influência das condiçôes climáticas nesta também é apontada como um aspecto negativo pelos adolescentes que participaram do estudo realizado por Sá et al. (2013). Estes resultados também reafirmam o que os estudos internacionais têm apontado sobre a dificuldade de acesso a serviços de saúde e à falta de serviços especializados, de lazer e comércio existente em regióes rurais (DAVIES et al., 2002; FRANCIS et al., 2006).

Quando questionados sobre os serviços existentes na região onde vivem e também a respeito dos serviços que julgavam necessária a existência, os participantes apontam principalmente a existência de alguns serviços ligados ao comércio, como supermercados e restaurantes, destacando sua insatisfação com tais serviços, e indicando a necessidade de mais possibilidades de lazer como uma prioridade.

Sá et al. (2013) também verificaram esta ausência de serviços - ou de serviços de qualidade - nos espaços rurais, relatada pelos adolescentes participantes de seu estudo, e pontuam que é direito de todo cidadão ter acesso a serviços públicos, como saúde, segurança e habitação de qualidade. De acordo com estes autores, tais serviços, quando oferecidos à comunidade, podem favorecer o desenvolvimento das crianças e adolescentes, além de melhorar sua qualidade de vida (SÁ et al., 2013).

Wedig e Menasche (2009) realizaram uma discussão interessante, ao pontuar que, ao mesmo tempo em que os jovens valorizam o espaço rural como lugar de bem viver, também pode ser observada uma valorização da estética urbana, o que pôde ser observado pelos autores através, por exemplo, das vestimentas que portam os jovens rurais, que hoje em nada se diferenciam daquelas dos jovens da cidade, bem como na valorização que atribuem aos espaços da cidade. Tal consideração também se associa aos resultados aqui apresentados, a respeito das percepçóes dos adolescentes sobre a região onde vivem, já que apontam a necessidade de mais serviços semelhantes aos existentes no espaço urbano e certo acesso a estes serviços nestes espaços urbanos, implicando em uma necessidade de deslocamento, que também é considerado por eles como uma dificuldade.

No entanto, com a transformação das alternativas e as formas de comunicação, esta dimensão parece também estar implicando em uma nova realidade e aprendizado para estes jovens, o que pode influenciar em como irão, mais em médio prazo, vivenciar estas mudanças. Por exemplo, permanecer no meio rural, mas ter acesso mais rápido à tecnologia, mais informação, espaços e relacionamentos virtuais, dentre outros, de forma semelhante ao que tem ocorrido com os adolescentes, de forma geral, em relação ao fenômeno da globalização.

Assim, hipotetiza-se que, para estes adolescentes, a área rural, apesar de oferecer um repertório menor de oportunidades, ainda é um local onde se considera positivo viver. Os adolescentes parecem valorizar aspectos positivos do rural, porém com a influência e o desejo de uniáo de tais aspectos com outros aspectos de áreas urbanas, que também são valorizados.

Por fim, a partir dos resultados encontrados no presente estudo e pensando nos objetivos propostos, supóe-se que a vivência de dificuldades relacionadas à saúde mental parece impactar pouco na percepção que os adolescentes participantes apresentam sobre as questóes colocadas (família, escola, amigos, área rural de moradia), na medida em que eles demonstram pertencer a um contexto que, embora seja apontado como restrito em termos de possibilidades de atividades, garante o pertencimento a grupos e ambientes, o que, por um lado, pode proteger e amenizar o sofrimento, e por outro, pode torná-lo uma experiência solitária e pouco compartilhada. Mais estudos que focalizassem essa populaçáo e esta realidade seriam importantes no sentido de ampliar a compreensão sobre a vivência cotidiana do sofrimento psíquico em adolescentes que vivem em áreas rurais.

De qualquer forma, o presente estudo contribui, para além da questâo da saúde mental dos adolescentes que residem em áreas rurais, para uma maior compreensão a respeito de como adolescentes que vivem nestas regióes as percebem, bem como a forma como encaram suas famílias, sua escola e as relaçóes com amigos, fornecendo subsídios para reflexóes e planejamento de ações e políticas públicas que envolvam o contexto rural, bem como novas questôes a serem exploradas em futuras investigaçôes.

\section{Limitações do Estudo}

O presente estudo apresentou algumas limitações, como o pequeno número de sujeitos participantes, a realização da pesquisa em uma única região rural e o não contato com adolescentes de regióes rurais mais distantes. Além disso, aponta-se que a seleção dos participantes com dificuldades relacionadas à saúde mental somente via indicação dos profissionais da USF, sem nenhuma avaliação mais específica, também pode ser considerada uma limitação, embora o critério para indicação estivesse claramente definido para 
tais profissionais, ou seja, adolescentes vinculados à USF por conta de dificuldades de saúde mental.

\section{Conclusão}

O presente estudo, de caráter exploratório e comparativo, contribuiu com elementos importantes a respeito do cotidiano de adolescentes com dificuldades relacionadas à saúde mental - e também daqueles que não vivenciam esta problemática - residentes em áreas rurais, dando voz aos mesmos.

O estudo possibilitou uma visão inicial acerca da saúde mental da população adolescente residente em regióes rurais, investigando qualitativamente a percepção destes adolescentes acerca de suas famílias, relações com amigos, escola, aspectos positivos e negativos da vida. Assim, considera-se que as informações aqui apresentadas oferecem um retrato inicial sobre o qual pode começar a ser pensado o processo de adolescer no contexto rural, bem como a saúde mental de adolescentes moradores de áreas rurais. Além disso, vários apontamentos a serem investigados por pesquisas futuras foram levantados.

Dessa forma, identifica-se a relevância deste estudo, no sentido de possibilitar o contato com um campo pouco investigado e que apresenta grandes possibilidades e necessidades de pesquisas, além de açôes relacionadas à promoção da saúde mental e também a outras esferas de atenção (educaçáo, assistência social, cultura, dentre outras).

Considera-se que novos estudos, que deem continuidade à investigação da saúde mental de adolescentes e da população rural em geral, são necessários para que as peculiaridades desta população possam ser mais bem compreendidas e, assim, subsidiem as reflexôes e o planejamento de açôes mais efetivas direcionadas a jovens residentes em áreas rurais.

\section{Referências}

AMPARO, D. M. et al. Adolescentes e jovens em situação de risco psicossocial: redes de apoio social e fatores pessoais de proteçáo. Revista Estudos de Psicologia, Campinas, v. 13, n. 2, p. 165-174, 2008.

AMSTALDEN, A. L. F.; HOFFMANN, M. C. C. L.; MONTEIRO, T. P. M. A política de saúde mental infanto-juvenil: seus percursos e desafios. In: LAURIDSEN-RIBEIRO, E.; TANAKA, O. Y. Atenção em saúde mental para crianças e adolescentes no SUS. São Paulo: Hucitec, 2010. p. 33-45.

AVANCI, J. Q. et al. Fatores associados aos problemas de saúde mental em adolescentes. Psicologia: Teoria e Pesquisa, Brasília, v. 23, n. 3, p. 287-294, 2007.
BARDIN, L. Análise de conteúdo. Lisboa: Ediçōes 70, 2006.

CID, M. F. B. Saúde mental de escolares: um estudo de prevalência e de fatores de risco e proteção. 2011. $141 \mathrm{f}$. Tese (Doutorado em Educação Especial) - Universidade Federal de São Carlos, São Carlos, 2011.

CID, M. F. B.; MATSUKURA, T. S. Problemas de saúde mental em escolares e seus responsáveis: um estudo de prevalência. Revista de Terapia Ocupacional da Universidade de São Paulo, São Paulo, v. 25, n. 1, p. 1-10, 2014.

COLLINS, W. A. et al. Contemporary research on parenting: the case gor nature and nurture. American Psychologist, Washington, v. 55, n. 2, p. 218-232, 2000.

COSTA, A. G.; LUDERMIR, A. B. Transtornos mentais comuns e apoio social: estudo em comunidade rural da Zona da Mata de Pernambuco, Brasil. Cadernos de Saúde Pública, Rio de Janeiro, v. 21, n. 1, p. 73-79, 2005.

DAVIES, L. et al. Rural life of us: young people and workers with young people in country Victoria. Victoria: Centre for Adolescent Health, 2002.

DELFINI, P. S. S.; REIS, A. O. A. Articulação entre serviços públicos de saúde nos cuidados voltados à saúde mental infanto-juvenil. Cadernos de Saúde Pública, Rio de Janeiro, v. 28, n. 2, p. 357-366, 2012.

DINIZ, L. R. Um espelho para se contemplar: a adolescência em discursos de adolescentes da zona rural. 2010. 128 f. Dissertação (Mestrado em Psicologia) - Universidade Federal de Pernambuco, Recife, 2010.

FARIA, N. M. X. et al. Estudo transversal sobre a saúde mental de agricultores da serra gaúcha. Revista de Saúde Pública, São Paulo, v. 33, n. 4, p. 391-400, 1999.

FARIA, N. M. X. et al. Processo de produçáo rural e saúde na serra gaúcha: um estudo descritivo. Cadernos de Saúde Pública, Rio de Janeiro, v. 16, n. 1, p.115-128, 2000.

FLEITLICH, B. W.; GOODMAN, R. Epidemiologia. Revista Brasileira de Psiquiatria, São Paulo, v. 22, p. 2-6, 2000. Suplemento 2.

FLEITLICH, B.; GOODMAN, R. Social factors associated with child mental health problems in Brazil: cross sectional survey. Britsh Medical Journal, Reino Unido, v. 323, n. 7313, p. 599-600, 2001.

FLEITLICH, B.; GOODMAN, R. Prevalence of child and adolescent psyquiatric disorders in southeast Brazil. Journal of Child and Adolescent Psychiatry, Baltimore, v. 43, n. 6, p. 727-734, 2004.

FRANCIS, K. et al. Rural adolescents' attitudes to seeking help for mental health problems. Youth Studies Australia, Australia, v. 25, n. 4, p. 42-49, 2006.

GAMM, L.; STONE, S.; PITTMAN, S. Mental health and mental disorders: a rural challenge. In: GAMM, L. et al. Rural Healthy People 2010: a companion docu- 
ment to healthy people. Texas: University System Health Science Center, School of Rural Public Health, Southwest Rural Health Research Center, 2003. p. 165-170.

GOMES, A. A.; ROZEMBERG, B. Condiçóes de vida e saúde mental na zona rural de Nova Friburgo - RJ. Psicologia: Ciência e Profissão, Brasília, v. 20, n. 4, p. 1629, 2000.

GOODMAN, R. et al. The Ilha de Maré study: a survey of child mental health problems in a predominantly African-Brazilian rural community. Social Psiquiatry and Psiquiatric Epidemiology, Berlin, v. 40, n. 1, p. 11-17, 2005.

LEONE, C.; GALLO, P. R. Saúde do jovem, início do século XXI, Brasil. In: LAURIDSEN-RIBEIRO, E.; TANAKA, O. Y. Atenção em saúde mental para crianças e adolescentes no SUS. São Paulo: Hucitec, 2010. p. 47-74.

MANZINI, E. J. Considerações sobre a elaboração de roteiro para entrevista semi-estruturada. In: MARQUEZINE, M. C.; ALMEIDA, M. A.; OMOTE, S. (Org.). Colóquios sobre pesquisa em Educação Especial. Londrina: UEL, 2002. p. 11-25.

MARQUES, L. F.; DELL'AGLIO, D. D. Relaçóes com a escola e fatores psicossociais positivos na adolescência. In: COLAÇO, V. F. R.; CORDEIRO, A. C. F. Adolescência e juventude: conhecer para proteger. São Paulo: Casa do Psicólogo, 2013. p. 81-100.

MATSUKURA, T. S. et al. Saúde mental infantil em contextos de desvantagem socioeconômica: fatores de risco e proteção. Cadernos de Terapia Ocupacional da UFSCar, São Carlos, v. 22, n. 2, p. 251-262, 2014.

PAFFER, A. T. et al. Prevalence of common mental disorders in mothers in the semiarid region of Alagoas and its relationship with nutritional status. São Paulo Medical Journal, São Paulo, v. 130, n. 2, p. 84-91, 2012.

PAULA, C. S.; MIRANDA, C. T.; BORDIN, I. A. S. Saúde mental na infância e adolescência: revisão dos estudos epidemiológicos brasileiros. In: LAURIDSEN-RIBEIRO, E.; TANAKA, O. Y. Atenção em saúde mental para crianças e adolescentes no SUS. São Paulo: Hucitec, 2010. p. 75-92.

PESCE, R. P. et al. Risco e proteção: em busca de um equilíbrio promotor de resiliência. Psicologia: Teoria $e$ Pesquisa, Brasília, v. 20, n. 2, p. 135-143, 2004.

ROZEMBERG, B. O consumo de calmantes e o "problema de nervos" entre lavradores. Revista de Saúde Pública, São Paulo, v. 28, n. 4, p. 300-308, 1994.

SÁ, D. G. F. et al. Fatores de risco para problemas de saúde mental na infância/adolescência. Psicologia: Teoria e Pesquisa, Brasília, v. 26, n. 4, p. 643-652, 2010.

SÁ, M. S. B. et al. Avaliação do sofrimento psíquico: transtorno psiquiátrico menor em adolescentes da localidade de Ururaí. Perspectivas Online: Ciências Humanas e Sociais Aplicadas, Campos dos Goytacazes, v. 3, n. 6, p. 1-15, 2013.

SAPIENZA, G.; PEDROMÔNICO, M. R. M. Risco, proteção e resiliência no desenvolvimento da criança e do adolescente. Psicologia em Estudo, Maringá, v. 10, n. 2, p. 209-216, 2005.

SCHMIDT, M. L. G.; GODINHO, P. H. Um breve estudo acerca do cotidiano do trabalho de produtores rurais: intoxicaçóes por agrotóxicos e subnotificação. Revista Brasileira de Saúde Ocupacional, São Paulo, v. 31, n. 113, p. 27-40, 2006.

SEIXAS, S. R. C. et al. Diagnósticos e medicalização: algumas consideraçóes sobre depressão e subjetividade em Nazaré Paulista, Apa Cantareira, São Paulo, Brasil. Mudanças: Psicologia da Saúde, São Paulo, v. 18, n. 1-2, p. 7-19, 2010.

SILVA, V. Jovens de um rural brasileiro: Socialização, educação e assistência. Cadernos CEDES, Campinas, v. 22 , n. 57 , p. $97-115,2002$.

SOUZA, M. T. S.; OLIVEIRA, A. L. Fatores de proteção familiares, situações de risco, comportamentos e expectativas de jovens de baixa renda. In: DELL'AGLIO, D. D.; KOLLER, S. H. Adolescência e juventude: vulnerabilidades e contextos de proteção. São Paulo: Casa do Psicólogo, 2011. p. 47-76.

SQUASSONI, C. E. Confiabilidade, validade e estudo dos padróes normativos da versão brasileira do Social Support Appraisals (SSA). 2012. $124 \mathrm{f}$. Tese (Doutorado em Educação Especial) - Universidade Fderal de São Carlos, São Carlos, 2012.

VIEIRA, R. S. Tem jovem no campo! Tem jovem homem, tem jovem mulher. In: ALVES, M. Coletânea sobre estudos rurais e gênero. Brasília: Ministério do Desenvolvimento Agrário, 2006. p. 195-213.

VITOLO, Y. L. et al. Parental beliefs and child-rearing attitudes and mental health problems among schoolchildren. Revista de Saúde Pública, São Paulo, v. 39, n. 5, p. 716-724, 2005

WANDERLEY, M. N. A ruralidade no Brasil moderno, por un pacto social pelo desenvolvimento rural. In: CONSEJO LATINOAMERICANO DE CIENCIAS SOCIALES - CLACSO. ¿Una nueva ruralidad en America Latina? Ciudad Autónoma de Buenos Aires: CLACSO, 2001. p. 31-44.

WEDIG, J. C.; MENASCHE, R. Entre o campo e a cidade: o lugar do consumo na mobilidade material e simbólica de jovens rurais. In: PINTO, M. L.; PACHECO, J. K. Juventude, consumo \& educação 2. Porto Alegre: ESPM, 2009. p. 95-112.

WORLD HEALTH ORGANIZATION - WHO. The world health report 2001 - Mental health: new understanding, new hope. Geneva, 2001. 


\section{Contribuição dos Autores}

Maria Fernanda e Letícia participaram igualmente de todas as fases de desenvolvimento e confecção do presente artigo. Todos os autores aprovaram a versão final do texto.

\section{Fonte de Financiamento}

\section{PIBIC/CNPq/UFSCar.}

\section{Notas}

${ }^{1}$ Tomamos por rural o conceito de Wanderley (2001), que considera o rural como um universo integrado ao conjunto da sociedade brasileira e ao contexto atual das relações internacionais, que não é um universo isolado e com lógica exclusiva de funcionamento e reprodução, porém que mantém particularidades históricas, sociais, culturais e ecológicas, que o recortam como uma realidade própria, da qual fazem parte, inclusive, as próprias formas de inserção na sociedade que o engloba. 